\title{
Amiodarone-induced thyrotoxicosis: four cases and a review of the literature
}

\author{
S. KEIDAR \\ M.D.
}

\author{
E. GRENADIER \\ M.D.
}

\author{
A. Palant \\ M.D. \\ Department of Cardiology, Lady Davis Carmel Hospital, Haifa, Israel
}

\begin{abstract}
Summary
Hyperthyroidism is a rare side effect of amiodarone treatment.

Four patients with this untoward effect are described One patient with mild hyperthyroidism before treatment with amiodarone, developed prolonged severe resistant thyrotoxicosis 6 months after initiation of this drug. A second patient with Wolf-ParkinsonWhite syndrome and paroxysmal atrial fibrillation was successfully stabilized with amiodarone for 18 months. However, the arrhythmia recurred and the thyroid function tests were found to be elevated. In 2 other patients only slight elevation of the thyroid function tests were found without clinical manifestations 4 months after treatment with amiodarone had been initiated.

\section{Introduction}

Amiodarone is an iodine-containing drug, similar to thyroxine. It was found to be effective in the treatment of angina pectoris and as an antiarrhythmic agent. Side effects are few, the most common of which is the appearance of microdeposits in the cornea; photodermatitis, hypothyroidism and, rarely, hyperthyroidism have been reported. Four patients with hyperthyroidism due to treatment with amiodarone are described and the literature is reviewed.
\end{abstract}

\section{Case reports}

\section{Case 1}

A 68-year-old woman suffering from ischaemic heart disease of 4 months' duration, had been referred complaining of palpitations which proved to be due to paroxysms of atrial fibrillation. Attempts to treat this with digoxin, propranolol, quinidine, procainamide and disopyramide failed and a regimen of $600 \mathrm{mg}$ amiodarone daily was instituted and after 2 weeks reduced to $400 \mathrm{mg} /$ day for the $\stackrel{\circ}{\circ}$ next 6 months. This treatment was successful, without $\triangle$ recurrence of any symptom. Plasma thyroxine (T4) $\vec{z}$ before treatment was $11.8 \mu \mathrm{g} / \mathrm{dl}$ (normal, $4 \cdot 5-11 \cdot 5$ ). After 6 months the patient complained of increased irritability, sweating, diarrhoea and a loss of $9 \mathrm{~kg} \bullet$ in weight despite a normal appetite. Physical amination revealed no exophthalmos or goited : Thyroid function tests showed: plasma T4, $18 \mu \mathrm{g} / \mathrm{d} ; ;$ T3 uptake-45.3\% (normal: $30-40$ ) and free thyroxine index (FTI), 23.1 (normal: 5-11). Amiodarone was discontinued and the patient was treated $\stackrel{\circ}{\propto}$ with a variety of antithyroid drugs which, because they $\overrightarrow{\vec{P}}$ caused severe leucopenia, were stopped. It has to be응 noted that since amiodarone was discontinued the patient has not relapsed into atrial fibrillation. After 6 months plasma T4 is still elevated at $16 \cdot 1 \mu \mathrm{g} / \mathrm{dl}$.

\section{Case 2}

The second case was that of a 63-year-old man suffering from the Wolf-Parkinson-White syndrome 8 with frequent attacks of rapid atrial fibrillation. Treatment with quinidine, procainamide, verapamilo and prajmaliumbitartrat all failed and treatment with amiodarone, $400 \mathrm{mg} /$ day, was initiated successfully을 and continued for 18 months. At the end of this period, attacks of rapid atrial fibrillation recurred \% but there were no other symptoms and signs of 0 hyperthyroidism. Thyroid function tests showed N T4, $13 \mu \mathrm{g} / \mathrm{dl}$; T3 uptake, 45\%; and FTI, 15.3.0 Amiodarone was discontinued and, without further treatment, thyroid function tests returned to normal $\frac{}{\Phi}$ within one month.

\section{Case 3}

A 63-year-old man complained of palpitations of 
5 years' duration, which were found to be due to paroxysmal atrial tachycardia. After receiving various antiarrhythmic drugs to no avail, amiodarone $400 \mathrm{mg}$ daily was begun. Thyroid function tests checked before treatment were within normal limits. During 4 months of treatment there has been no recurrence of the arrhythmia but T4 was found to be $17 \mu \mathrm{g} / \mathrm{dl}$ and the FTI, 15.1. There were no clinical signs of thyrotoxicosis. The drug was stopped and the T4 returned to normal within one month.

\section{Case 4}

A 52-year-old man with no specific chest pain was known to have had paroxysmal atrial fibrillation for the last 10 years. Medical history revealed no other illnesses. Physical examination was normal and routine laboratory tests including thyroid function tests were normal. Treatment with quinidine, propranolol and oxprenolol was ineffective. A trial of amiodarone $200 \mathrm{mg} /$ daily for one month failed to control the atrial fibrillation. At this time thyroid function tests were T3 uptake, $38.1 \%$ T T , 14.0 $\mu \mathrm{g} / \mathrm{dl}$; FTI, 15.2. There were no clinical signs of thyrotoxicosis. One month after treatment with amiodarone had been discontinued, T3 uptake was $40 \cdot 1 \%$; T4, $11 \cdot 4 \mu \mathrm{g} / \mathrm{dl}$ and FTI, $13 \cdot 0$.

\section{Discussion}

Amiodarone is a benzofuran derivative, with a thyroxine like structure. The drug is used in patients with angina and various cardiac arrhythmias.

Amiodarone accumulates mainly in muscle and adipose tissue during the first month of intake of $400 \mathrm{mg}$ daily, which is the regular dose, following which a steady state ensues. The metabolism of the drug yields about $9 \mathrm{mg}$ of iodine/day, which is 100 times the normal dietary intake. The half-life of amiodarone in the body is between 28-100 days according to different authors (Broekuysen, Caruel and Sion, 1969; Massin et al., 1971). However in some cases the drug has been known to be active 11 months after it was discontinued.

Prichard, Bramah and Hurley (1975) described the influence of amiodarone on thyroid function in 12 patients suffering from angina. The patients received $600 \mathrm{mg}$ daily of the drug for 6 weeks and it was found that amiodarone caused a significant increase in serum thyroxine, and a parallel fall in the level of T3. Berger et al. (1976), investigating the effect of amiodarone in normal patients, suggested that the drug affected thyroid hormone metabolism possibly by reducing de-iodination of T4 to T3 and inducing a preferential production of $3^{\prime}, 5^{\prime}, 3^{\prime}$ triiodothyronine. Amiodarone also increased the response of TSH to TRH. No signs of hyperthyroidism or hypothyroidism were found in those patients.
Hypothyroidism following amiodarone has been described in a few patients (Massin et al., 1971; Hazard et al., 1973; Rosenbaum et al., 1976). Hyperthyroidism, on the other hand, has not been frequently reported (Jonckheer et al., 1973; Chapelle, Naouri and Wolff, 1976; Héraud et al., 1974; Rivière et al., 1974). Rosenbaum et al. (1976) treated 252 patients with diverse supraventricular and ventricular arrhythmias with amiodarone, and found only 2 patients showing symptomatic hyperthyroidism.

Wheeler et al. (1979) treated 52 patients with amiodarone without any effects on thyroid function. Jonckheer et al. (1973) described the largest series of patients with hyperthyroidism and classified them into 3 groups.

The first group consisted of patients with past thyroid diseases, such as Grave's disease, who developed a clinical and laboratory picture of thyrotoxicosis, similar to the first patient described in the present series.

The second group included patients without any past thyroid disease, who had discontinued taking amiodarone for at least 3 months before the appearance of signs of hyperthyroidism. The hyperthyroidism was of the kind created by an overdosage of thyroxine.

The third group, consisted of those patients who did not have any past records of thyroid malfunction and who developed, during treatment with amiodarone, thyrotoxic symptoms. This is probably the largest group and has also been described by others (Chapelle et al., 1976; Héraud et al., 1974; Rivière et al., 1974; Savoie et al., 1975); it is exemplified by the last 3 patients in the present series. The patients described by Savoie et al. (1975) who developed hyperthyroidism after receiving amiodarone or iodine, were characterized by (1) intake of iodine compounds for at least one month; (2) no previous history of thyroid disease before treatment; (3) a small enlargement of the gland which disappeared afterwards; (4) a reduced ${ }^{131}$ I uptake even following TSH; (5) a latent period of hypothyroidism until the gland function returned to normal. Thyroxine levels were found to be higher in these patients than in patients suffering from thyrotoxicosis of different aetiology, and higher doses of antithyroidial drugs and $\beta$-blockers are needed and for a longer period of time.

The diagnosis in these cases is based on the thyroxine level in the blood while the radioactive iodine uptake is of no diagnostic value.

Among the patients described above, the first, although suffering from prolonged severe hyperthyroidism during treatment with amiodarone, did not have any episode of atrial fibrillation; she probably suffered from mild hyperthyroidism before 
having been treated with amiodarone and this explains the duration and severity of her sickness. On the other hand, an invaluable clue to the correct diagnosis in the second case was the recurrence of paroxysmal atrial fibrillation. In the other 2 cases, because of the awareness to the subject, the drug had been discontinued before any clinical symptoms occurred.

It is concluded that any recurrence of sinus or atrial tachycardia, or atrial fibrillation, in a patient treated with amiodarone should cause one to suspect hyperthyroidism.

\section{Acknowledgment}

We wish to thank Mr G. Alpan for his help in writing this article.

\section{References}

Berger, A., Dnichert, D., Nicod, P., Jenny, M., LemarchAND, T., BÉRAND, S. \& VAllotTon, M.B. (1976) Effect of amiodarone on serum triiodothyronine, reverse triiodothyronine, thyroxin and thyrotropin. Journal of Clinical Investigation, 58, 255.

Broekuysen, J., Caruel, R. \& Sion, R. (1969) Étude comparée du transit et du métabolisme de l'amiodarone chez diverses espèces animales et chez l'homme. Archives internationales de pharmacodynamie et de thérapie, 177, 340.

Chapelle, M., Naouri, R. \& Wolff, F. (1976) L'Hyper- thyroïdie à l'amiodarone. Archives des maladies du coeur des vaisseaux et du sang. Paris, 10, 1073.

hazard, J., Perlemuter, L., Bernheim, R., Guilhaume, B \& Richiet, D. (1973) Insuffisances thyroïdiennese secondaires à un traitement par l'amiodarone. Nouvelle. presse médicale, 2,691 .

Heraud, G., Braud, J., Roux, E. \& Leonard, Ch. (1974) Hyperthroïdie et amiodarone. Nouvelle presse médicale, $3 \div$ 1727.

JonCKNeER, M.H., Blockx, P., Kaivers, R. \& Wyffels, G음 (1973) Hyperthyroidism as a possible complication of the treatment of ischaemic heart disease with amiodarone. $\mathbb{Q}$ Acta cardiologica. Brussels, 28, 192.

Massin, J.P., Thomopoulos, P., Karam, J. \& Savoie, J.C.ึ (1971) Le risque thyroïdien d'un nouveau coronarodilateuriodé à l'amiodarone. Annales d'endocrinologie. Paris, 32; 437.

Prichard, D.A., Bramah, N.S. \& Hurley, P.J. (1975) Effects of amiodarone on thyroid function in patients with ischaemic heart disease. British Heart Journal, 37, 856.

Rivière, J., Roger, P., Dugravier, F., Broustet, P. DAubèze, J. \& Convi, C. (1974) Hyperthyroïdie et amiodarone. Nouvelle presse médicale, 3, 2503.

Rosenbaum, B.M., Chiale, P.A., Halpern, M.S., Nau, G.J. of Przybylski, J., LeVI, R.J. Lazzari, J.U. \& Elizari, M.V U (1976) Clinical efficacy of amiodarone as an antiarrhythmic

Savoie, J.C., Massin, J.P., Thomopoulos, P. \& LÉger, F.을 (1975) Iodine-induced thyrothoxicosis in apparently? normal thyroid gland. Journal of Clinical Endocrinology and Metabolism, 41, 685.

Wheeler, P.J., Puritz, R., Ingram, D.V. \& Chamberlain, D.A. (1979) Amiodarone in the treatment of refractory $\vec{C}$ supraventricular and ventricular arrhythmias. $P$ graduate Medical Journal, 55, 1. 